\title{
Why loot boxes could be regulated as gambling
}

Authors: Aaron Drummond1,2*, James D. Sauer2,3, Lauren, C. Hall1,2, David Zendle4, Malcolm R. Loudon1

\begin{abstract}
Affiliations:
1School of Psychology, Massey University, Palmerston North 4424, Manawatu, New Zealand 2International Media Psychology Laboratory 3Psychology, School of Medicine, University of Tasmania, Australia.

4 Department of Computer Science, University of York, York, North Yorkshire, United Kingdom
\end{abstract}

*To whom correspondence should be addressed. Email: a.drummond@massey.ac.nz

Note: This is not the copy of record. The copy of record can be accessed here 
Do purchasable randomised reward mechanisms in video games (loot boxes) constitute gambling? Opinions often rest on whether virtual items obtained from loot boxes have real-world value. Using market data from real transactions, we show that virtual items have real-world monetary value and therefore could be regulated under existing gambling legislation.

Loot boxes - digital containers of randomised virtual items (See Box 1) included in some video games, often purchased for real-world money-bear striking similarities to conventional forms of gambling 1 . An examination of psychological features of loot boxes in PC and Console games released in 2016-2017 revealed that almost 50\% of reviewed loot box systems were psychologically akin to conventional gambling activitiesı. Perhaps because of this, problem-gamblers spend more on these mechanisms than non-problem gamblers2,3. Thus, policy-makers are debating whether loot boxes require regulation as bona-fide gambling, but some countries have already enacted legislation 4.

Though legal definitions vary, three key components are commonly necessary for bona-fide gambling (Box 1). Where loot boxes deliver random items, the 'chance' component is satisfied. Where loot boxes are purchased for money, the 'consideration' requirement is satisfied. Some games require users to purchase keys/intermediary currency to trade for loot boxes. As real money (a price) is paid for the key/currency, the intermediary has value, and subsequent trade for loot boxes can be considered a barter trade. This may also satisfy consideration requirements in some jurisdictions. However, a key point of contention for policymakers remains whether items obtained from loot boxes have value (satisfying the 'prize' requirement). For example, an industry submission to a recent Australian Senate inquiry stated: “...items obtained in a loot box are not money or considered 'anything else of value""5. Some argue that because items obtained from loot boxes are worthless, and because 
no player incurs losses from opening loot boxes, loot boxes are not gambling5,6. This argument has swayed regulatory decisions. For instance, the UK Gambling Commission historically stated: “...where in-game items obtained via loot boxes are confined for use within the game and cannot be cashed out it is unlikely to be caught as a licensable gambling activity."7.

The assertions that virtual items have no value and that no player makes a loss from opening loot boxes are empirically testable. Despite differences in the way economic theories define value, almost all assert market price as the best indicator of value9. Although some game service agreements state that virtual items are licensed to, not owned by, players, ownership is not a pre-requisite for value. Price also indexes value for services (Box 1). Thus, the price of these items remains an empirical indicator of value irrespective of ownership status. We synthesize market data from several sources demonstrating that: a) where virtual items are tradable for real-world money, substantial transactions of real currency have occurred (suggesting that these items have real-world value); b) most virtual items are sold for less than the cost of a loot box (representing real financial losses), challenging the assertion that no player who opens a loot box makes a loss; and c) gamers who do (cf. do not) purchase virtual items also spend significantly more in total on games, demonstrating a willingness to spend additional money acquiring virtual items and the additional financial value of these items over and above the game itself. Finally, one rationale for including loot boxes may be to reduce purchase cost of games in line with 'freemium models', where games are cheap, and lost revenue recouped through virtual item purchases10. If true, virtual items would not capture additional revenue, but be an alternative mechanism to capture the same revenue. Refuting this argument, we demonstrate a positive relationship between video game and virtual item spending. This violates the perfect substitution relationship predicted under utility theory: If virtual items were simply an alternative form of monetisation total spending 
would remain constant, and loot box spending would simply displace other gaming-related spending. Contrary to claims from industry representatives5 and researchers6, virtual items appear to have value to users, implying that systems requiring users to pay for the randomised distribution of such items might be suitable for regulation under existing gambling legislation in many jurisdictions.

\section{Do virtual items have value and can players lose?}

Arguments that virtual items have no value rest largely upon the perception that virtual items cannot be sold for real-world money1,5. However, this overlooks the legitimate marketplaces (e.g., Steam Marketplace) and grey market economies that allow people to monetise virtual items 1.

Although information for grey market economies is scarce, we interrogated the Steam Marketplace Application Program Interface, determining whether items from three popular games (Counter Strike Global Offensive [CS:GO] ; DOTA 2; Player Unknown's Battlegrounds [PUBG]) were being bought and sold for real-world money. Using a 2-step process, we obtained comprehensive sales figures for these virtual items. First, using Python, we obtained the details of the top 1,001 most traded items for CS:GO and DOTA 2, and the entire list of PUBG's 317 unique tradable items (see online supplementary materials for details). Next, for each item, we used the "Beautiful Soup" Python web scraping library to extract the volume and price of all sales from the time the item was listed until data collection began (CS:GO: September 11, 2018; DOTA 2: September 20, 2018; PUBG: May 7, 2019). This generated a list of 2,319 items purchasable for an average of 947 days ( $\mathrm{SD}=609$ days; Range: 1-1,946 days).

These data revealed approximately 1.45 billion sales worth $\$ 1,004,955,106.92$ USD in real currency. At an aggregate level, these items clearly have substantial monetary value. 
At the individual level, the average sales price for an individual item was $\$ 5.03$ (SD $=$ \$34.83, Range: \$0.03-\$743.80). Critically, most items were sold for less than the cost of purchasing a loot box (\$2.49), demonstrating a financial loss in real terms, and contradicting the common argument that loot boxes are not gambling because no player loses upon opening a loot box6. Indeed, the overwhelming majority of players incur financial losses when onselling loot box items, with $\sim 93 \%$ of sales recouping less than the purchase price. For context, European style roulette wheels have an approximate $97 \%$ loss rate for bets placed on one number.

It might be tempting to infer that value is limited to cases where after-markets exist to monetise items. However, where legitimate marketplaces are absent, spontaneous grey markets have emerged (where possible) to allow virtual item trading 1 . This suggests that the items themselves have intrinsic worth and this value is simply indexed by price where markets are available. The emergence of grey markets suggests that markets develop to allow trading of valuable items, rather than being a pre-requisite for value.

\section{Does spending on virtual items displace spending on games or generate} additional revenue?

In a recent survey, $\sim 35 \%$ of participants reported purchasing a loot box and $52 \%$ reported purchasing virtual items in the previous month2. The strictest interpretation of the claim that virtual items have no value implies that players would spend no money on them. This is obviously untrue. A more lenient interpretation would suggest gamers are priceinsensitive: they are willing to spend a specific amount on gaming-related purchases, and virtual items are simply an alternative monetisation method to capture this revenue. According to this interpretation, including virtual items in a game's monetisation architecture should produce a substitution effect where players spend less money purchasing games and more on virtual items. If behaving perfectly rationally, and assuming virtual items have no 
real value, gamers should substitute the amount they spend on virtual items for the amount they spend on games, creating a negative relationship reflecting preferences between perfect substitutes. Even if gamers are not perfectly rational (and, as humans, they are not), if virtual items have no value then spending on virtual items should be negatively associated with spending on games due to peoples' preferences to maximize satisfaction within budgetary constraints9. This was not the case.

Gamers who purchased any virtual items spent more in total on video games than gamers who did not purchase virtual items (Table 1). There was no substitution effect. Limiting analyses to participants who did not regularly play games with legitimate marketplaces to monetise items did not qualitatively alter the relationship. The effect was also similar for users who had purchased non-randomised virtual items (i.e., not using loot boxes). Participants who had purchased loot boxes also spent more in total than participants who had not purchased loot boxes, though this effect was smaller, reflecting the larger spending variability associated with loot boxes (cf. non-randomised virtual items). In sum, gamers who purchase virtual items spend more on video games than gamers who do not, irrespective of whether these items are acquired directly or via randomised loot boxes, and whether items can be legitimately monetised.

Figure 1 shows the positive relationship between video game spending and spending on virtual items. On average, gamers spend approximately $33 \mathrm{c}$ more on virtual items for every $\$ 1$ they spend buying video games, $B=0.33, p<.001$ (See online supplementary materials for details). Although limiting analyses to participants who did not regularly play games with legitimate marketplaces to monetise items slightly reduced the effect, the relationship remained significant, $B=0.11, p=.002$. Demonstrably, virtual items have enough value, at least to some gamers, to warrant purchase with real-world money. Moreover, the positive relationship between spending on video games and spending on 
virtual items shows that virtual items are not simply an alternative monetisation technique, but a supplemental monetisation stream: Players spend real money purchasing virtual items in addition to the money spent purchasing games. This relationship does not require legitimate marketplaces to monetise these items. These data contradict the notion that virtual items have no value: providing direct evidence against the predicted substitution effect.

\section{Conclusion}

Digital regulation and governance often lag behind technology and innovation, creating unregulated or under-regulated spaces. Although researchers and gamers acknowledge the value of virtual items and the digital economies they constitute, legislation reflects archaic notions that digital items do not have real value. This has posed obstacles to regulation and contributed to novel risks such as increased mental distress associated with the exposure of problem gamblers to loot boxes which deliver items through systems that closely approximate gambling, but which often do not carry the legal definitions, warning labels, or associated protections accompanying bona-fide gambling 3 (see also supplementary material). We have demonstrated that virtual items have monetary value to gamers irrespective of whether they can be cashed out. Therefore, randomised virtual items ("loot boxes") purchased for real money likely satisfy the requirements of value needed to meet legal definitions of gambling in many jurisdictions. Legislators should recognise the value of virtual items and consider regulating loot box sales.

\section{References}

1. A. Drummond, J. D. Sauer, Video game loot boxes are psychologically akin to gambling. Nature Human Behaviour 2, 530-532 (2018).

2. D. Zendle, P. Cairns, Loot boxes are again linked to problem gambling: Results of a replication study. PloS one 14, e0213194 (2019).

3. W Li, D. Mills, L. Nower, The relationship of loot box purchases to problem video gaming and problem gambling. Addictive behaviors, 97, 27-34, (2019)..

4. M. McCaffrey, The Macro Problem of Microtransactions: The Self-Regulatory Challenges of Video Game Loot Boxes. Business Horizons, forthcoming, (2019). 
5. IGEA, Gaming micro-transactions for chance-based items. Senate Environment and Communications References Committee. Available at https://www.aph.gov.au/DocumentStore.ashx?id=c6e6cf74-093d-47c7-aa46b68aeb22140f\&subId=613645, (2018).

6 D. King, P. Delfabbro, Loot box limit-setting is not sufficient on its own to prevent players from overspending: A reply to Drummond, Sauer, and Hall. Addiction, (2019).

7. UK Gambling Commission, Loot boxes within video games. https://www.gamblingcommission.gov.uk/news-action-and-statistics/news/2017/Lootboxes-within-video-games.aspx, (2017).

8. I.N. Rose, Gambling and the Law ${ }^{\circledR}$ : an introduction to the law of internet gambling. UNLV Gaming Research \& Review Journal, 10(1), 1-14, (2006).

9. D. Rutherford, Routledge dictionary of economics. Routledge, (2013).

10. N. Chen, A. N. Elmachtoub, M. Hamilton, X. Lei,. Loot Box Pricing and Design. Available at SSRN 3430125, (2019)

Competing interests: The authors declare no competing interests.

Data availability: The Steam Market data are available at https://osf.io/8xmrt/ and the survey data are available at https://osf.io/2jgph/

Acknowledgements: We thank Christopher Ferguson for comments on an earlier version of this manuscript. 


\section{Box 1. Definitions for Key Terms}

Gambling: Legal definitions of gambling differ across countries and jurisdictions. Three key elements of commonality exist across most jurisdictions: Consideration, Chance, and Prizes.

Consideration: entry requirements, requires players to expend something of value (usually money) to enter.

Chance: outcomes must be chance-based, not skill-based.

Prize: players can win something of value.

Value: Price or intrinsic worth of a good/service. Current economic theory predominantly emphasises price to index value9.

Virtual Item: An item without physical corpus and, for present purposes, purchasable for real world money directly, or via paid loot box. 
Fig. 1. The relationship between gamers' spending on video games and virtual items contained within video games, $B=0.33, p<.001$. Data drawn from Zendle and Cairns2. 
Table 1 Average spending on video games in the last month by gamers who purchased virtual items and gamers who did not purchase virtual items (SDs in brackets). Effect sizes in Cohen's $d$. Data drawn from Zendle and Cairns2.

\begin{tabular}{|c|c|c|}
\hline $\begin{array}{c}\text { Gamers who purchased } \\
\text { virtual items }\end{array}$ & $\begin{array}{l}\text { Gamers who did not } \\
\text { purchase virtual items }\end{array}$ & \\
\hline \multicolumn{3}{|c|}{ All responders $(n=1,516)$} \\
\hline$\$ 165.47$ & $\$ 56.40$ & $t(1,514)=13.70, p<.001$ \\
\hline$(\$ 189.77)$ & $(\$ 78.19)$ & $d=0.75$ \\
\hline \multicolumn{3}{|c|}{ Gamers who did not regularly play games with legitimate marketplaces $(n=300)$} \\
\hline$\$ 120.04$ & $\$ 57.15$ & $t(298)=5.99, p<.001$ \\
\hline$(\$ 106.53)$ & $(\$ 73.47)$ & $d=0.68$ \\
\hline \multicolumn{3}{|c|}{ Gamers who purchased non-randomised virtual items $(n=1,516)$} \\
\hline$\$ 172.18$ & $\$ 63.81$ & $t(1,514)=13.79, p<.001$, \\
\hline$(\$ 197.84)$ & $(\$ 81.92)$ & $d=0.72$ \\
\hline \multicolumn{3}{|c|}{ Gamers who purchased Loot Boxes $(n=1,516)$} \\
\hline$\$ 187.45$ & $\$ 84.13$ & $t(1,514)=12.35, p<.001$ \\
\hline$(\$ 216.94)$ & $(\$ 108.90)$ & $d=0.30$ \\
\hline
\end{tabular}

